\title{
Stress-Zone Based Support Technology of Large Section Coal Roadway
}

\author{
Feng Cai ${ }^{1,2^{*}}$ \\ ${ }^{1}$ Institute of Geotechnical Engineering, China University of Mining and Technology, Beijing, 100083, China \\ ${ }^{2}$ China National Coal Group Corporation, Beijing 100120, China
}

\begin{abstract}
As a new method to support gate roadways, rock bolting has been widely used in the big coal enterprises for its superiority. The disturbed stress field of surrounding rock and anchor pre-stress field were divided into 3 areas in consideration of $\sigma_{1}, \sigma_{3}$. The surrounding rock failure form and characteristic were analyzed in combination with parameter $f$, the failure mechanism was explained using the slip line theory, furthermore, the rock bolting mechanism and its arrangement were studied. After roadway excavation, the tensile stress area appeared at the surface of the surrounding rock. The failure type changes from shallow tension-shear form into deep compression-shear form and the failure shape is an "incense burner", surrounding by high risk failure area in butterfly shape. The maximum principle stress in roof appears discontinuous distribution because of layers separation. The failure type of surrounding rock is intensity-stress environment-weak plane control model. The internal reason of roadway macroscopic failure is the displacement between the surface plastic area and the deep elastic region along the tangential direction of slip line. In condition of rock bolt support, there is one-way tensile stress area in small range at the surface of surrounding rock, inside is the bidirectional compressive zone in uniform distribution form, stress environment is improved by the superposition of anchor pre-stress and disturbed stress field, anchor rock bolt arrangement and pre-tightening force distribution is decided according to the distribution of $\mathrm{f}$ parameter. Finally, supporting method and parameter reasonability was proved by the roadway deformation monitoring, damage depth drilling peep test in the 8101 transportation roadway in a mine.
\end{abstract}

Keywords: stress zoning, coal roadway, failure mechanism, rock bolt support, pre-stress field

\section{Introduction}

The stability of roadway support is very important to the safety and sustainable development of coal mine. In recent years, the focus of China's coal mining industry began to move to West China, the thick-extra thick coal seam is developed in the West. The latest technology and equipment have been put in to service, the occurrence condition of thick coal seam and the increasing of productivity lead to the cross section of the roadway increasing continually, hence, it is more difficult to control the surrounding rock. At present, the most common way to support the roadway is rock bolt (cable) support (Wang 2007); Scholars have been deeply studied on the mechanism of rock bolt. It is reported (Wang et al 2012, Gao 2007, Zhang and Yuan 2006) that the influence of rock bolt on physical and mechanical parameters of coal and rock mass in the anchorage zone, It is believed that the rock bolt can improve the peak strength of surrounding rock, especially the post peak strength, and the failure mode of rock mass under the rock bolt support is analyzed. It is reported (Wang et al 2014, Xiao et al 2013, Li et al 2007, Yan et al 2012), according to different geological conditions, the failure mechanism of surrounding rock and supporting technology of the whole coal roadway were studied. Focus on the failure mechanism of roadway surrounding rock, different forms of high strength support methods were proposed, which achieved good results. It is reported (Wang et al 2012a, Zhang et al 2011, Wang et al 2012b, Kang et al 2010, Zhang et al 2010, Kang et al 2007) that the supporting mechanism of pre-stressed anchor was analyzed from the point of the distribution of the maximum principal stress in the pre-stressed anchor field, and the influence of the rock bolt support parameters and surrounding rock characteristics on the supporting effects were studied. Based on the latest research results, this paper analyzed the failure mechanism of surrounding rock of coal roadway, proposed the high strength anchor net cable combined supporting technology based on the feature of stress zoning distribution of surrounding rock, to provide reference for the coal roadway rock bolt (cable) support technology.

\section{Surrounding Rock Failure Mechanism of Coal Roadway}

Large number of indoor coal-rock physical and mechanical parameters test shown that, Coal-rock damage form is shown as brittle failure, shear failure and plastic flow at different stress states. In order to get the failure mechanism of surrounding rock in large section coal roadway, based on the geological conditions of the 8801 working face of a certain mine, used the Flac $^{3 \mathrm{D}}$ to establish numerical model and analyze it.

* Corresponding Author: F. Cai, caifeng868@163.com, phone: +86 10-82256878 


\subsection{Numerical model}

Take the transportation roadway of the 8101 working face as the numerical simulation object. The roadway is a rectangular cross-section, with size of $5400 * 4500 \mathrm{~mm}$, placed along the floor of coal seam, the roof of roadway is $1.6 \mathrm{~m}$ thick coal body. The model was $64 \mathrm{~m}$ high and $66 \mathrm{~m}$ wide. Coal-rock mass destruction follow the M-C Strength Criterion, interlayer interface was established between the rock layers to simulate layered sedimentary rock mass. The 4 sides and the bottom set the displacement constraints, set 5.2 MPa stress at the top of model as boundary condition, the side pressure coefficient $\lambda$ was 0.33 . The stress zoning of roadway surrounding rock after excavation disturbance was analyzed, the failure mechanism and characteristics of surrounding rock.

\subsection{Stress zoning and meaning parameter $f$}

The stress zoning of surrounding rock was divided as follow, defined the parameter $\mathrm{k}$, when $\sigma_{1}>0, \sigma_{3}>0, \mathrm{k}=0$, the surrounding rock was in bi-directional tension state. When $\sigma_{1}<0, \sigma_{3}>0, \mathrm{k}=1$, the surrounding rock is in unidirectional tension state. When $\sigma_{1}<0, \sigma_{3}<0, \mathrm{k}=2$, the surrounding rock was in bi-directional compression state. The principal stress of the M-C yield condition is expressed by Eq. (1), its physical meaning was the difference between the radius of the Mohr stress circle and its vertical distance from the center to the intensity curve. When $\mathrm{f}<0$, the surrounding rock was in elastic state; $f=0$, the surrounding rock was in the limit equilibrium state; $f>0$, the surrounding rock was in the state of plastic failure.

$$
f=\frac{1}{2}\left(\sigma_{1}-\sigma_{3}\right)-C \cos \varphi+\frac{1}{2}\left(\sigma_{1}+\sigma_{3}\right) \sin \varphi
$$

After the initial balance of the numerical model, the stress state and parameter $f$ distribution of each rock layers in numerical model are shown in Figure 1. Before the excavation disturbance, each rock layer is in a bi-directional compression state. The difference of the physical and mechanical parameters of each rock layer causes the initial $f$ value to be layered, but the $f<0$.

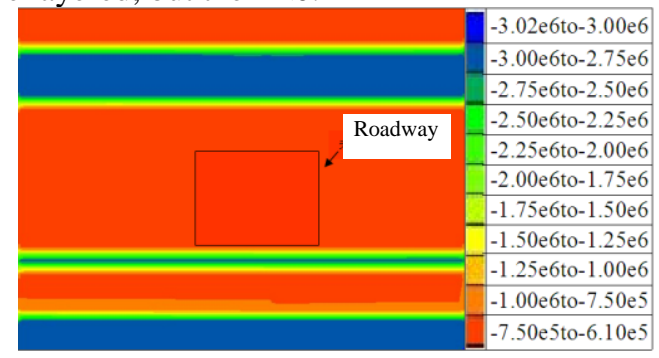

Figure 1. Parameter $\mathrm{f}$ distribution of Initial stress field.

\subsection{Disturbed stress zoning division}

After the excavation of the roadway, the stress state of the surrounding rock is shown in Figure 2. There are a large range of tensile stress zones in the roof and floor of the coal seam. Because of uneven pressure, a small range of tensile stress zone appears in the two sides of the roadway. There are a small range of tensile stress zone appears at the lower part of the immediate roof for the bending deformation.
According to the resist compressive but non-tensile properties of coal and rock media, it can be concluded that the surrounding rock is in the tensile stress zone is most likely to reach its strength limit and enter the failure state.

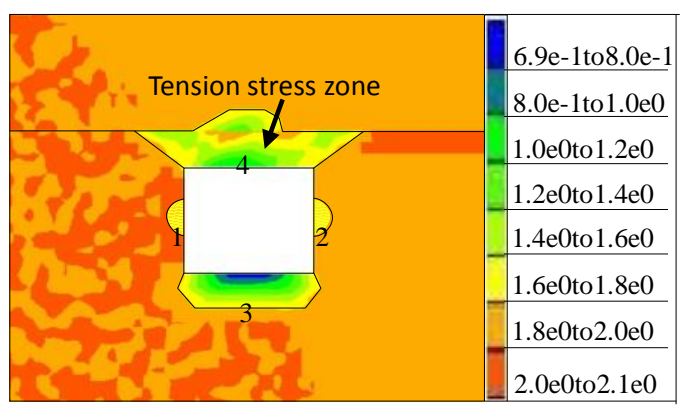

Figure 2. Disturbed stress partition.

Set the monitoring line in the middle of the roadway roof to monitoring the maximum principal stress changes, as shown in Figure 3. The maximum principal stress in the coal roof is changed from the lower part to the higher part gradually transition from the tensile stress into the compressive stress. And the maximum principal stress is mutate into tensile stress again when entering the immediate roof mudstone, the discontinuity of the maximum principal stress distribution occurs in the roof rock strata due to the development of interlayer separation. Because of the small mining space in roadway, the development range of roof separation is small, as shown in Figure 3, the bedding plane between the top-coal and the immediate roof mudstone is separated from the layer due to shearing dislocation. The maximum principal stress of the upper strata above the immediate roof mudstone gradually changes into the continuous distributed compressive stress.

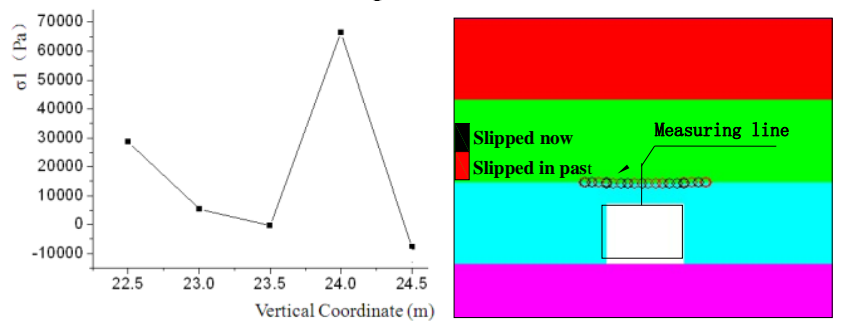

Figure 3. Roof separation and maximum principle stress distribution.

\subsection{Distribution of parameter $f$}

The roadway excavation before it hasn't been affected by exploitation, the distribution of the parameter $\mathrm{f}$ is show in Figure 4, The surrounding rock failure mode was incense burner, small range, and it is limited within coal seam, immediate roof and immediate floor. According to the disturbing stress field, coming to a conclusion that 1, 2, 3, and 4 zones belong to the tensile-shear failure zone, the rest of the damaged coal and rock mass belongs to the compressive-shear failure zone. The distribution characteristics of the two types of surrounding rock indicate that roadway surrounding rock gradually change from the surface tensile-shear failure to the depth of compressive- 
shear failure. At the deeper high confining pressure region, surrounding rock gradually transits to the elastic state. Around the destruction area, there is a large area with high destruction risk located around the destruction area, in shape of "butterfly". If the shallow destruction area cannot be controlled effectively, the destruction area gradually develops to the deep rock along time; the high risk zone gradually changes into the destruction area. The rock damage range at the four corners is small, and install rock bolts in these four positions can increase the effective anchorage length, meanwhile it can improve the support effect. The roof and floor sandstone has high strength, with strong anti-disturbance ability and far away from the roadway. After excavation, the parameter $\mathrm{f}$ of the distribution is almost unchanged, retain the initial value-3e6.

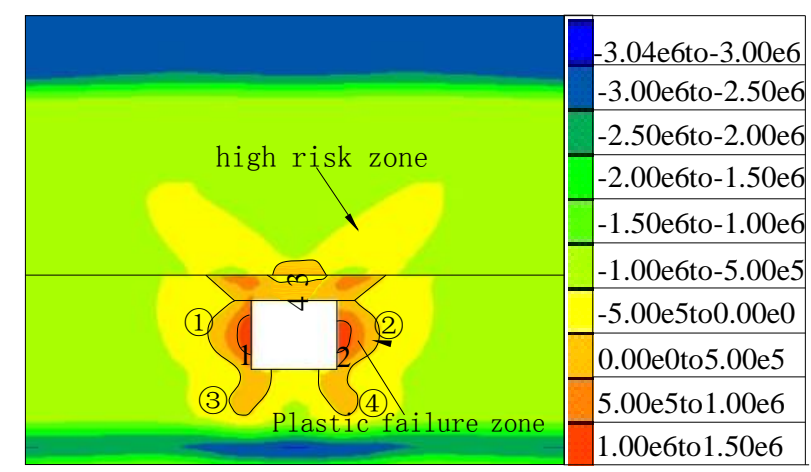

Figure 4. Parameter $\mathrm{f}$ distribution after extraction.

\section{Roadway Rock Bolt (Cable) Supporting Mechanism}

According to the roadway rock damage conditions, the essence of the roadway support is improving the strength of surrounding rock, improving the stress environment and restricting fracture weak surface separation and extension of shear misalignment. Rock grouting can increase the physical and mechanical constants of coal-rock mass and enhance the strength of surrounding rock directly, but this art is rare in mining roadway for the complex craft. High pre-stressed force rock bolt (cable) support raise the strength by improve the surrounding rock stress environment, as well, can increase the residual internal friction angle of broken rock, in order to changes the tensile zone of the shallow surrounding rock into compressive zone, it can increase the confining pressure of deep coal-rock mass, meanwhile, limits the occurrence of interlayer separation, and avoids the occurrence of discontinuous stress field distribution.

\subsection{Rock bolt (cable) support mechanism}

If neglect the crustal stress, the rock bolt (cable) pre-stressed field is shown in Figure 5 (a). There is an obvious biaxial tensile stress area at the end of the sidewall rock bolts, and the biaxial compressive stress zone appears in the middle of the rock bolt. Both sides of the anchor cable of the tunnel roof are formed approximate symmetrical distribution of biaxial compressive stress area, near the surface of the roadway. The pre-stressed field of anchor cable and rock bolt are superposed; there is no biaxial tensile stress zone at the anchor end. It can prevent the anchorage body from the deep rock mass separation under the gravity effect, and the stress distribution in the center of the rock bolt is more uniform. The compression stress zone at sidewalls and roof are connected together, controlling the deformation and failure of roadway; a smaller range of one-dimensional tensile stress area is formed in the circle of the roadway. The surrounding rock is easy to collapse this region.

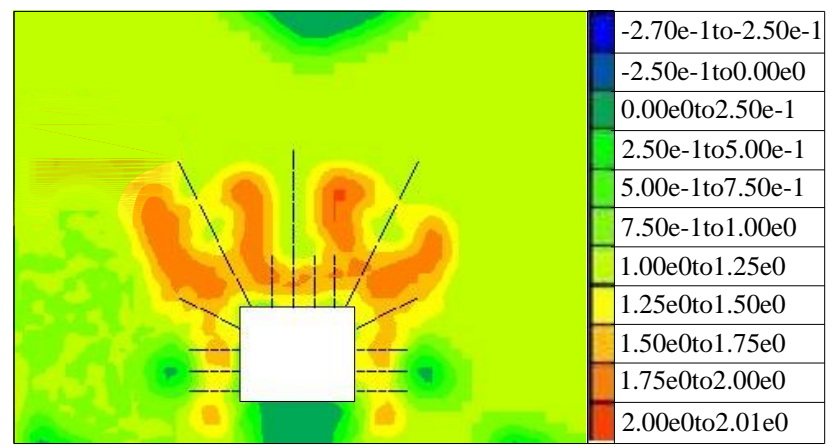

(a) Pre-stress partition

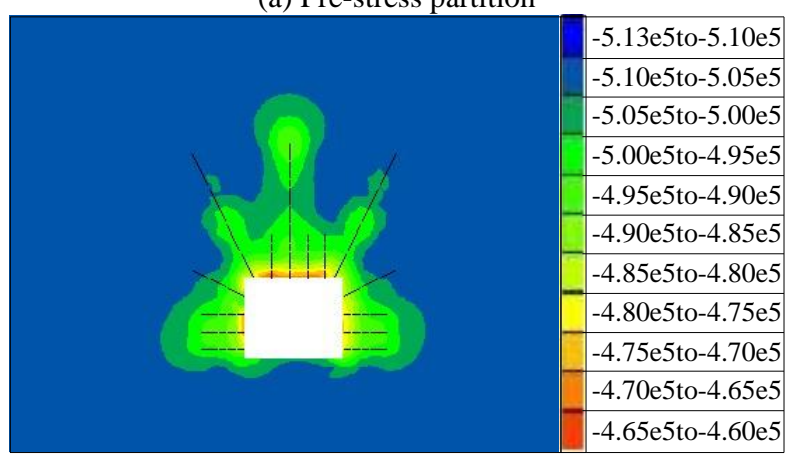

(b) Parameter f distribution

Figure 5. Pre-stress partition and parameter f distribution.

Under the action of cable pre-stress field, the distribution of $\mathrm{f}$ value is shown in the Figure 5 (b). When the rock bolt (cable) is not parallel to the vertical direction of the roadway, the pre-stress field is not easy to spread, and the pre-stressing force needs to be increased to improve the supporting effect; the F value increases obviously under the influence of pre-stress field, indicating that compared with no stress of coal- rock mass, the pre-stress field did not improve the stress environment. The coal rock mass is more easily damaged in the anchorage area, but the stress area of coal-rock mass can be improved by superposition of the prestress field and the disturbed stress field in the disturbance area. Its principle is shown in Figure 6.

Coal-rock mass in the free state, the principal stress of each point is zero, the Mohr's circle is reduced to $\mathrm{O}$ point, the value of $\mathrm{f}$ is the length of OA; Under the action of the pre-stressed field, The principal stress $\sigma_{21}, \sigma_{23}$ respectively in the biaxial compression zone. The value of $\mathrm{f}$ is the length of the $\mathrm{CD}$, according to the numerical simulation results, the CD length is slightly smaller than the OA length; the principal stress of a point on the surface of the roadway subjected to excavation disturbance is $\sigma_{11}$ and $\sigma_{13}$ 
respectively. Under the condition of un-support, the value of $\mathrm{f}>0$, the rock enters the destruction state.

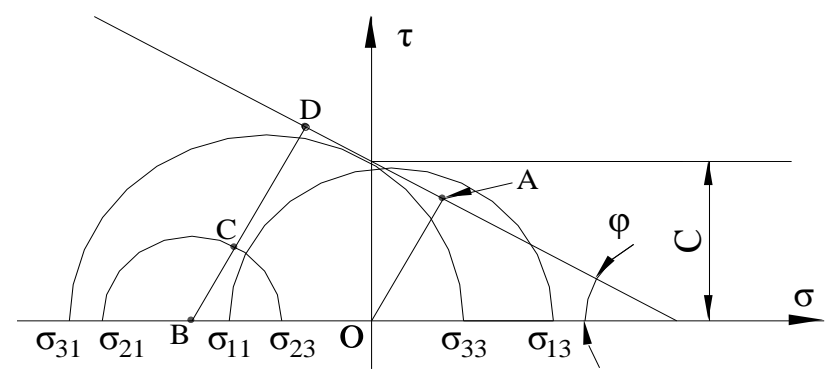

Figure 6. Superposition of the stress.

After the rock bolt (cable) support, the pre-stressing stress field is superimposed with the disturbance stress field, the principal stress in the failure state point is changed to $\sigma_{31}$, $\sigma_{33}$, the value $\mathrm{f}<0$ in the unsupported state. Under action of the pre-stressed rock bolt (cable) supporting, this point is still in the elastic state after the tunnel excavation disturbance.

\subsection{Rock bolt (cable) support design}

According to the parameter $\mathrm{f}$ value distribution, the length of sidewalls rock bolts should be greater than the failure zone's width, the rock bolts at the shoulders should insert in an elevation angle, the bottom corner rock bolts in a depression angle. Both locates rock bolts should increase the pre-tightening force, thereby, increasing the effective anchorage length and ensure the effective force diffusion. The others help rock bolt to enter the roadway surface vertically, to ensure the middle of the rock bolt can form pre-stress field of continuous biaxial compression. The roof rock bolts are perpendicular to the roof, ensure effective diffusion of the preloaded force, and can improve tensile stress environment of the top-coal body of major roof. The middle of the roof anchor cables are perpendicular to the roof onto the roadway, it can control the integral sinking of the rock bolt anchoring body and the anchor section to form a biaxial tensile stress zones, it also can increase the confining pressure of the roof $\mathrm{A}, \mathrm{B}$ caving danger zone, and avoid the roof damage developing into the deep rock. As shown in Figure 7.

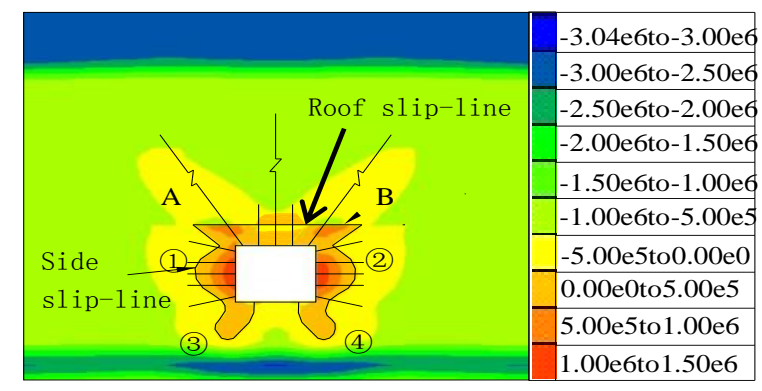

Figure 7. Rock bolt arrangement.

\section{Engineering Applications}

The 8101 working face of a Mine is the first mining face of the reserve regions. The main mining 7 \# coal seam, the average thickness is $6.3 \mathrm{~m}$, coal seam are stable, Protodyakonov coefficient is $1.1 \sim 1.3$, the immediate roof and floor are mudstone. The working face adopt full-seam mining method, transport roadway excavating along the seam floor, roadway cross-sectional area reach $24.8 \mathrm{~m}^{2}$. According to the deformation failure mechanism of surrounding rock, the high strength rock bolt-mesh-cable combined support technology is adopted to improve the stability of roadway.

\subsection{Determination of support parameters}

The rock bolt for roof and sidewall is high strength rock bolts, with diameter $22 \mathrm{~mm}$, length $2400 \mathrm{~mm}$. the roof row spacing is $850 \times 900 \mathrm{~mm}, 7$ rock bolts each row, the sidewall rock bolts spacing is $1000 \times 900 \mathrm{~mm}, 5$ rock bolts each raw. The cable is diameter $18.9 \mathrm{~mm}$ and length 7300 $\mathrm{mm}$, at spacing of $2000 \times 1800 \mathrm{~mm}$, place 3 cables every 2 rows rock bolts. The rock bolt supplemented by $120 \times 120 \times$ $10 \mathrm{~mm}$ high-strength rock bolt plate and $\Phi 14$ steel ladder beam, rock bolt pretension force $60 \mathrm{KN}$, the pretension force of 4 rock bolts at the roadway shoulder is $100 \mathrm{KN}$, to ensure the pre-stress field diffusion range. The Anchor cable use $300 \times 300 \times 16 \mathrm{~mm}$ high-strength plate, pretension force $100 \mathrm{KN}$. The metal meshes are installed on the roof and both sidewall, the layout shown in Figure. 8.

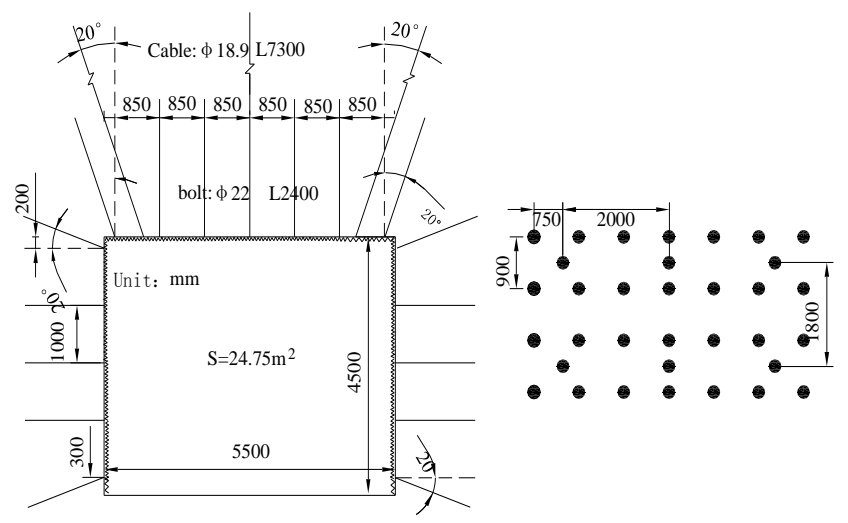

Figure 8. Supporting profile in 8101 transportation roadway.

\subsection{Analysis of roadway surface deformation}

After excavation of roadway, set the measuring station at the two sides of roadway, the middle of roof and floor, to the measured surface deformation. The surface displacement curve was shown in Figure 9. The surrounding rock mass is suddenly unloading after excavation, and the stress environment is changed from three directions compression suddenly to the bi-direction compressive, even tensile state. The displacement curve rises rapidly, lasted about 10 days. The average closing speed of roof and floor is $3.7 \mathrm{~mm} / \mathrm{d}$, the average closing speed of the two sides is $4.9 \mathrm{~mm} / \mathrm{d}$. As far away from tunnel face, surrounding rock deformation rate decreases, and the deformation tends to be stable, the effect period is about $40 \mathrm{~d}$. after reaching a stable state, the 
surrounding rock deformation rate below $0.15 \mathrm{~mm} / \mathrm{d}$, both sides moved close to amount of $84 \mathrm{~mm}$, roof and floor move close to amount of $57 \mathrm{~mm}$, the surrounding rock control effect of is better.


Figure 9. Surface deformation of roadway surrounding rock.

\subsection{Contrastive analysis of surrounding rock control effect}

Using CXK6 Mine Intrinsically Safe Drilling Imager to detect the surrounding rock failure condition of the roadway before and after the high strength rock bolt-net-cable combined support technology were used. The equipment can record the fracture development of the borehole wall by generate video, and the borehole imaging can be expanded into a planar graph for visual analysis.

Before the implementation of high strength rock bolt mesh - cable combined support technology, the peephole results are shown in Figure 10, the shallow roof of the roadway is seriously damaged, showing a broken state. There is an obvious delamination phenomenon at the interface between the top coal body and the immediate roof mudstone, the holes in the roadway both sides were located in the coal body, the strength of $3 \#$ was lower, drilling along the axial emergence of a large range of collapse hole phenomenon; deformation and failure observation surface of surrounding rock of test section: The roof and the Inner wall of the hole is smooth, no obvious damage and separation phenomenon, indicating that the high strength anchor (cable) under the action, the surrounding rock of 8101 roadway has been effectively controlled.

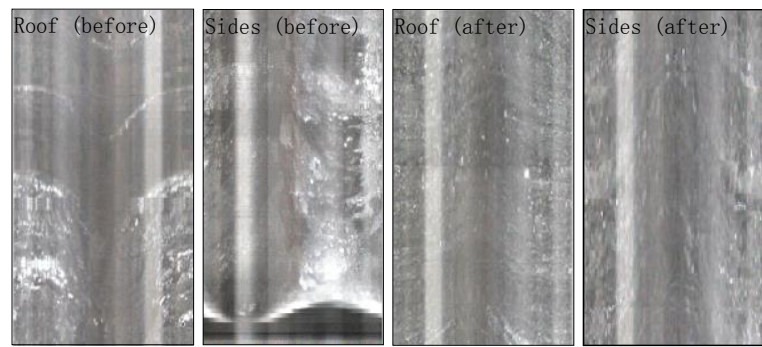

Figure 10. Comparison of surrounding rock failure feature.

\section{Conclusions}

(1) After the excavation of coal roadway, the tensile stress zone appears rapidly on the surface of the surrounding rock. The failure mode is changed from the surface shear failure mode to the deep compress-shear failure mode, and the failure form like "incense burner". There is a "butterfly" distribution of the damage zone in the periphery of the damaged area, roof interlayer weak surface abscission layer lead to discontinuous distribution of maximum principal stress.

(2) The failure of coal-rock mass belongs to strength stress environment - weak surface control type, the deformation and failure of the roadway along the axis of the roadway were regarded as plane strain, used the slip line theory to analyze the fundamental reason of roadway surrounding rock failure, draw the conclusion: the shearing deformation of the plastic zone around the elastic zone along the direction of the slip line.

(3) Under the action of pre-stressed anchor (cable), a small-scale uniaxial tensioned stress zone appears on the surface of the roadway, easily failure and caving, and its inner side is a nearly uniformly distributed bi-directional compressive stress region. The stress environment of surrounding rock can be improved by superposition of prestress field and disturbed stress field. Combined with the distribution of disturbance $\mathrm{f}$ value and the diffusion characteristics of pre-stress field, determine the reasonable distribution form of rock bolt (cable) and the size of the pretightening force.

\section{References}

Gao, M.Z., 2007. Stiffness analysis of rock bolt and anchor cable supporting for coal roadway. Journal of Mining \& Safety Engineering, 24(4): 396 - 400.

Li G.C., N. Zhang and Z.H. Liu, 2007. Prestress truss rock bolt support technology for coal roadway. Journal of Mining \& Safety Engineering, 24(2): 150 - 154.

Kang, H.P., J.H. Wang and J. Lin, 2010. Case studies of rock bolting in coal mine roadways. Chinese Journal of Rock Mechanics and Engineering, 29(1): 649 - 664.

Kang, H.P., T.M. Jiang and F.Q. Gao, 2007. Effect of pretensioned stress to rock bolting. Journal of China Coal Society, 32(1): 680 - 685. DOI: 10.13225/.cnki.jccs. 2009. 12.004

Wang, H.W., Y.D. Jiang, Y.X. Zhao, J. Zhu, R.Y. Shan, 2012a. Application of support technology with high strength and high pretension stress for weak-broken 
rocks. Journal of Mining \& Safety Engineering, 29(1): $474-480$.

Wang, J.H., 2007. New development of rock bolting technology for coal roadway in China. Journal of China Coal Society, 32(2): 113 - 118. DOI: 10.13225/j. cnki.jccs.2007.02.001.

Wang, Q., S.C. Li, Z. Li, W.T. Li, F.Q. Wang, B. Jiang, D.C. Wang, H.T. Wang, 2012b. Analysis of roof collapse mechanism and supporting measures in fault zone of coal roadway. Rock and Soil Mechanics, 33(10): 3093 3102. DOI: $10.16285 /$ j.rsm.2012.10.024.

Wang, W.J., L.Q. Luo and W.Z. Huang, 2014. Study on supporting failure mechanism and reasonable length of anchor cable in thick soft-weak roof of high-stress coal roadway. Journal of Mining \& Safety Engineering, 31(1): 17-21. DOI: 10.13545/j.issn1673-3363.2014.01. 003.

Xiao, T.Q., H.Z. Li and Y Xu, 2013. Breaking mechanism of shoulder rock bolt of deep coal roadway in tectonic stress area and its control. Rock and Soil Mechanics, 34(8): 2303 - 2308. DOI:10.16285/j.rsm.2013. 08.026.

Yan, H., F.L. He, T.F. Xu, H.J. Jiang, S. Gao, 2012. Experimental study of rock bolt and cable truss system for large cross-section coal roadways under high stress. Rock and Soil Mechanics, 33(2): 257 - 262. DOI: 10.16285/j.rsm.2012. s2.013

Zhang, N. and L. Yuan, 2006. Control principle of separating and broken roof rock strata in roadway. Journal of Mining \& Safety Engineering, 23(1): 34 - 38.

Zhang, N., G.C. Li and J.G. Kan, 2011. Influence of soft interlayer location in coal roof on stability of roadway rock bolting structure. Rock and Soil Mechanics, 32(9): 2753 - 2758. DOI: 10.16285/j.rsm.2011.09.038

Zhang, Z., H.P. Kang and J.H. Wang, 2010. Pre-tensioned stress coordination function analysis of rock bolt-cable anchor support in coal roadway. Journal of China Coal Society, $35(6)$ : $881 \quad-\quad 886 . \quad$ DOI: 10.13225/j.cnki.jccs.2010.06.004 